\section{Tracheal stenosis due to bilateral arterial} aneurysms

\author{
Neil C Munro, D Soppitt, R A L Brewis
}

\begin{abstract}
The case is presented of an 82 year old woman with breathlessness, stridor, and upper mediastinal widening on chest radiography. Computed tomographic scanning showed tracheal compression by aneurysms of the brachiocephalic and left common carotid arteries.
\end{abstract}

(Thorax 1994;49:183-184)

Respiratory distress due to tracheal obstruction by thoracic aortic aneurysms has been reported and, in some cases, successfully treated by surgical intervention. We present a case of tracheal stenosis produced by aneurysms of the brachiocephalic and left common carotid arteries.

\section{Case report}

An 82 year old woman presented via her general practitioner with a one year history of worsening breathlessness on exertion and mild dysphagia. She had had childhood bronchitis but no other features of asthma. She had been hypertensive and had angina for some years but there was no history suggestive of cardiac failure. Her current medication comprised a $\beta$ blocker, a calcium antagonist, and a thiazide diuretic.

Physical examination revealed a fit elderly woman. Stridor was present on deep inspiration but examination of the lungs was otherwise unremarkable. Her blood pressure was $200 / 110$, and the brachiocephalic artery was easily palpable in the right supraclavicular fossa. The heart sounds were normal.

Spirometric tracing demonstrated the initial

Department of

Medicine

N C Munro

R A L Brewis

Department of

Radiology

D Soppitt

Royal Victoria

Infirmary,

Queen Victoria Road,

Newcastle-upon-Tyne NE1 4LP

Reprint requests to:

Dr N C Munro.

Received 23 October 1992

Returned to authors

13 January 1993

Revised version received

8 March 1993

Accepted for publication

16 March 1993 straight line and "shoulder" appearance characteristic of large airways obstruction. The chest radiograph showed widening of the upper mediastinum with tracheal compression (fig 1). The initial clinical suspicion was of a retrosternal goitre, but thyroid isotope scan revealed a normal sized thyroid gland in the neck. A contrast enhanced computed tomographic scan of the thorax using $10 \mathrm{~mm}$ serial sections demonstrated tracheal compression by concurrent aneurysms of the brachiocephalic artery on the right and the common carotid artery on the left (fig 2). The aorta was of normal calibre and the remainder of the scan was unremarkable. In the absence of symptoms or signs of disease elsewhere in the respiratory tract, further investigation such as fibreoptic bronchoscopy was not pursued. Her symptoms have remained stable over a six month period with treatment aimed at optimal blood pressure control.

\section{Discussion}

Stridor, spirometric features of a large airways obstruction, and an upper mediastinal mass on chest radiography are most commonly encountered in patients with bronchogenic carcinoma, mediastinal lymphadenopathy, thymoma, or retrosternal goitre.

Acute respiratory distress with tracheal obstruction has been reported in patients with aneurysms of the aorta alone, or in conjunction with dilatation of the brachiocephalic (innominate) artery. ${ }^{12}$ Severe tracheal compression from a false aneurysm of the ascending aorta has also been described ${ }^{3}$ and, in a further report, difficulty resulting from tracheal obstruction was only encountered after induction of anaesthesia and intubation. ${ }^{4}$ Two further cases of fatal acute laryngeal compression from haematomas following rupture of thoracic aortic aneurysms have been recorded. ${ }^{5}$

Compression of the trachea by bilateral arterial aneurysms without associated thoracic aortic dilatation has not been described before. Our case is also unusual in that symptoms developed insidiously; previously reported cases of aneurysmal compression have presented acutely.

Surgical intervention in cases such as this would be extremely hazardous. Intraluminal expandable metal stents have been used to relieve symptoms resulting from obstruction of the large airways, most commonly by tumour. ${ }^{67} \mathrm{We}$ are not aware of any reports of

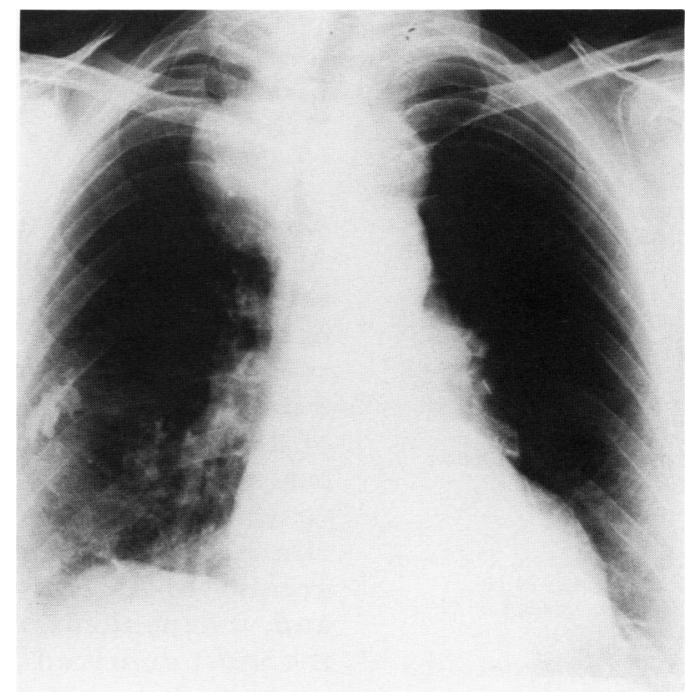

Figure 1 Chest radiograph showing widening of the upper mediastinum and tracheal compression. An area of pleural calcification of unknown aetiology is also seen in the right mid zone. 


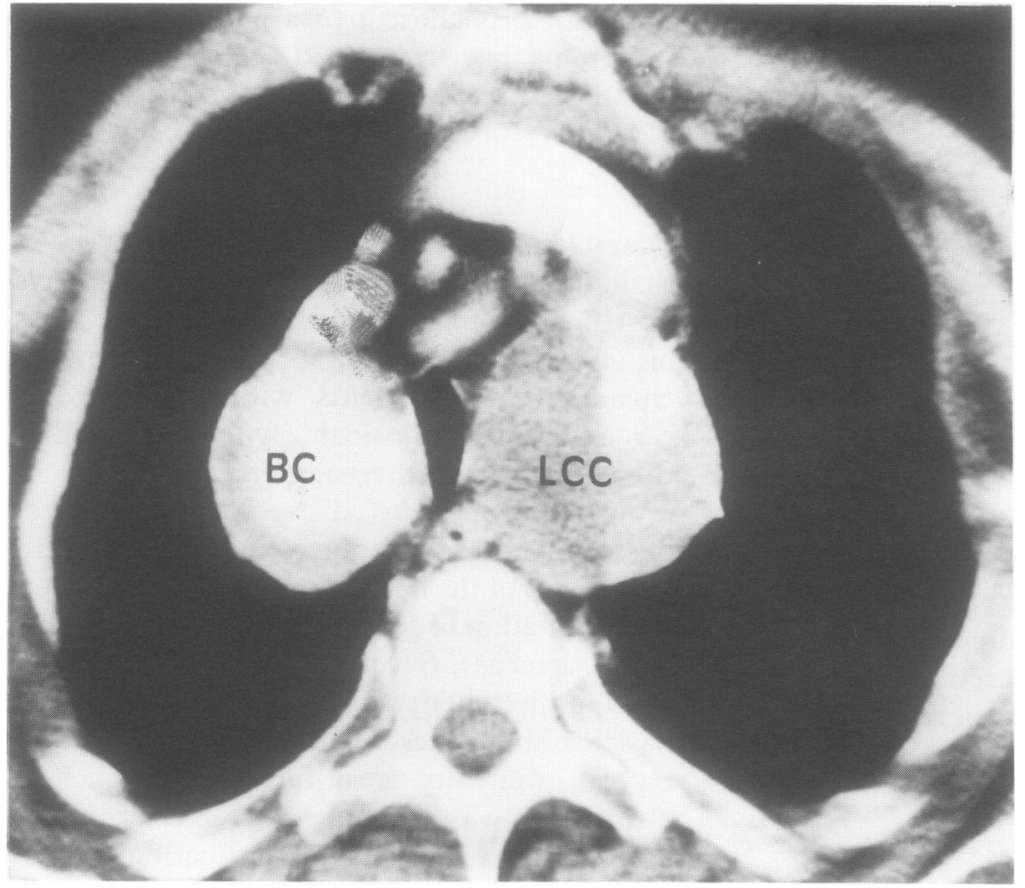

Figure 2 Computed tomographic scan section showing concurrent aneurysmal dilation of the brachiocephalic (BC) and left common carotid (LCC) arteries producing tracheal compression. their use in airways compression due to vascular aneurysms. A potentially fatal complication of stenting in this situation might be pressure necrosis leading to a bronchoarterial fistula. Medical management aimed at optimal control of blood pressure would seem the most appropriate course wherever possible.

We thank Miss Sharon Ritchie for secretarial assistance.

1 Murakami S, Urayama H, Kanehira E, Misaki T, Funaki Y, Iwa T. Successful emergency operation for tracheal obstruction caused by aneurysm of the aortic arch. NipponKyobu-Geka-Gakkai-Zasshi 1987;35:533-7.

2 Tominaga R, Tanaka J, Kawachi Y, Yoshitoshi M, Kohno $\mathrm{H}$, Shiki K, et al. Surgical management of respiratory insufficiency due to tracheobronchial compression by aneurysms of the ascending aorta and innominate artery. $f$ aneurysms of the ascending aorta

3 Nishiwaki K, Komatsu T, Shimada Y, Takeuchi E, Abe T. Severe tracheal compression caused by false aneurysm arising from the ascending aorta: successful airway management using induced hypotension and bronchoscopy. Anesthesiology 1990;73:1047-9.

4 Okutomi T, Shiraishi Y, Kato S, Ikeda K. A patient with bronchostenosis due to thoracic aortic aneurysm manifested by anaesthesia. Masui 1987;36:417-21.

5 Lindsay DC, Smith MCF, McQuillan PJ, Jordan MB. Laryngeal compression and stridor as the presenting feature of ruptured thoracic aortic aneurysm. $f$ Cardiovasc Surg 1989;30:864-6.

6 Simonds AK, Irving JD, Clarke SW, Dick R. Use of expandable metal stents in the treatment of bronchial obstruction. Thorax 1989;44:680-1.

7 George PJM, Irving JD, Mantell BS, Rudd RM. Covered expandable metal stent for recurrent tracheal obstruction. Lancet 1990;335:582-4.

\section{Childhood tuberculosis in Leeds, 1982-90: social and ethnic factors and the role of the contact clinic in diagnosis}

\author{
J M Goldman, C Teale, D B Cundall, \\ S B Pearson
}

The Leeds Chest

Clinic

J M Goldman

$S$ B Pearson

St James's University Hospital

C Teale

The General Infirmary at Leeds D B Cundall

Reprint requests to: Dr S B Pearson, The Leeds Chest Clinic, 74 New Briggate, Leeds LS1 6PH, Briggate

Received 28 October 1992 Returned to authors 9 February 1993 Revised version received 12 March 1993 Accepted for publication 6 May 1993

\begin{abstract}
A retrospective analysis of childhood tuberculosis in Leeds over a nine year period (1982-90) was performed which showed that the contact clinic is important for the early detection and treatment of disease in children. Two thirds of the cases of tuberculosis in children under 15 years were diagnosed and treated at the clinic. The incidence of tuberculosis was greater in Asian than in white children and, independent of race, was greater in the most deprived area of the city.
\end{abstract}

(Thorax 1994;49:184-185)

We have analysed the contribution of the screening services to the control of tuberculosis in children over the nine year period from the beginning of 1982 to the end of 1990 . The opportunity has also been taken to extend and strengthen our previous analysis of the ethnic and social factors influencing childhood tuberculosis. $^{1}$

\section{Methods}

In Leeds all tuberculosis notifications are forwarded to the chest clinic. In addition, copies of reports of positive microbiological and histopathological examinations are sent from laboratories within the city, allowing reminders about notification to be sent to clinical colleagues. Health visitors visit source cases, identify close contacts, and administer Heaf tests. All contacts then attend the chest clinic for reading of Heaf tests and chest radiographs if Heaf tests are positive.

In this survey all cases notified between January 1982 and December 1990 have been reviewed. Patients with atypical mycobacterial infections were not included in the analysis.

The population of Leeds is approximately 710000 including 19000 originating from the Indian subcontinent and 19000 belonging to other ethnic minority groups. ${ }^{2}$ The proportion of the population aged $0-14$ years was estimated as $34 \%$ people from the Indian subcontinent, $26 \%$ for other ethnic groups, and $18 \%$ for the white population..$^{23}$ The urban priority area of the city (population 200000 ) contains $60 \%$ of those claiming supplementary benefit, 